04

\title{
Эрозия катода в газовом дуговом разряде в области пороговых токов
}

\author{
(C) А.М. Мурзакаев \\ Институт электрофизики УрО РАН, \\ 620016 Екатеринбург, Россия \\ e-mail: Amurzak@mail.ru
}

Поступило в Редакцию 20 апреля 2021 г.

В окончательной редакции 16 июня 2021 r.

Принято к публикации 17 июня 2021 г.

Представлены результаты экспериментальных исследований удельной эрозии вольфрамовых катодов высокой чистоты после импульсных дуговых разрядов в чистом безмасляном сверхвысоком вакууме и в газах разной чистоты. Величина удельной эрозии в аргоне высокой чистоты не меняется по сравнению с величиной удельной эрозии электродов в чистом безмасляном вакууме. Величина удельной эрозии в „техническом“ аргоне меньше на 10-20\% по сравнению с величиной удельной эрозии электродов в безмасляном вакууме. Величина удельной эрозии в „техническом“ азоте меньше на 15-35\% величины удельной эрозии электродов в вакууме. Размеры частиц, образованных в газовых дугах, меньше размеров частиц, образованных в вакуумных дугах.

Ключевые слова: дуга в газе, удельная эрозия, эктонный механизм, частицы, электронная микроскопия.

DOI: 10.21883/JTF.2021.11.51524.114-21

\section{Введение}

Электрическая дуга в инертном газе с вольфрамовым заостренным катодом и охлаждаемым анодом нашла широкое применение в промышленности. Общее представление о газовых дугах можно найти в [1]. При холодных катодах и газовые, и вакуумные дуги имеют много общих характеристик, например, напряжение горения дугового разряда примерно одно и то же в вакууме и в газе при широком диапазоне изменения давления окружающего газа. Поэтому представлялось правдоподобным, что основные физические процессы в катодном пятне (КП) такие, как образование плазмы из материала катода, испарение материала катода и перенос тока в межэлектродном пространстве, остаются неизменными при добавлении газа в разрядную камеру. В $[2,3]$ выявлено снижение удельной эрозии на порядок в газовых дугах по сравнению с вакуумными дугами $[4,5]$. Для вакуумных дуг установлено, что эрозия катода состоит из трех компонентов: ионов, нейтральных паров и капель размером от 0.1 до $10 \mu \mathrm{m}$ [6-9]. Капли на первый взгляд являются скорее побочным продуктом, чем активным составляющим КП, так как они не влияют на электрические характеристики. Ионный ток составляет от 6 до 10\% от общего тока дуги и зависит от материала катода. Пары образуются у КП из-за нагрева катода и изза испарения жидких капель металла. По данным $[7,10]$, доля паровой эрозии составляет от нескольких процентов до $10-20 \%$ от общей эрозии и зависит от материала катода. На динамику фрагментов и ячеек КП влияет окружающий газ. На некотором расстоянии от центра КП затрудняется расширение плазмы металла [11-14]. Появления новых КП дальше области распространения плазмы материала катода означает, что их образование происходит из-за взаимодействия плазмы газа с поверхностью катода.

Известно, что в газах, реагирующих с электродами, поверхности электродов покрываются загрязняющими слоями. В воздухе поверхность электродов покрыта оксидами [15]. В [16] были обнаружены пленки азота толщиной $10 \mathrm{~nm}$ при давлении $670 \mathrm{~Pa}$ и толщиной два раза большей при давлении $1300 \mathrm{~Pa}$ В $[15,17,18]$ изучали влияние слоев загрязнения на типы пятен и их движение. Было обнаружено, что при увеличении давления газа начинают преобладать пятна первого типа, т.е. поверхностные загрязнения способствуют зажиганию новых КП на больших расстояниях от существующего.

Из анализа этих работ следует, что на эрозию электродов в вакууме и газах сильно влияет состояние поверхности (чистота) электродов. Из-за плохо определенных условий поверхности электродов большое разнообразие результатов трудно интерпретировать. Эти противоречивые данные о величинах удельной эрозии требуют более тщательной экспериментальной проверки.

\section{1. Материал и методика эксперимента}

Bсе эксперименты проводились в одной и той же камере из нержавеющей стали, снабженной смотровым окном. Блок-схема экспериментов приведена на рис. 1 . Во всех сериях экспериментов материал катода, анода и поджигающего электрода были изготовлены из вольфрамовой проволоки диаметром $0.1 \mathrm{~mm}$ и чистотой 99.98\%. Проволочные электроды готовились по следующей методике: для удаления графита (углерода) с поверхности 


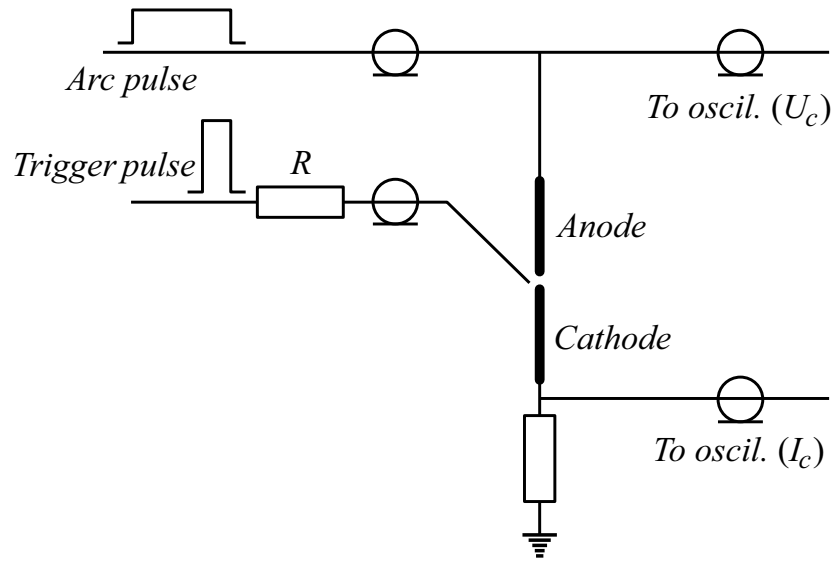

Рис. 1. Схема эксперимента.

проволоки после волочения и выравнивания поверхности проволока электрохимически полировалась, промывалась дистиллированной водой и этиловым спиртом. Вакуум получали откачкой безмасляными методами цеолитовым форвакуумным насосом при охлаждении жидким азотом и ионизационным магниторазрядным насосом. При постоянной откачке электроды очищались прогревом пропусканием тока через них при температуре чуть ниже точки плавления. Методика прогрева электродов подробно описана в [19]. По номограмме для расчета вольфрамовых проволочных катодов и подогревателей с известным диаметром и длиной проволоки получали величину тока для нагрева проволоки до необходимой температуры. В первой серии экспериментов температуру электродов измеряли еще пирометром. Полученные результаты практически не отличались. При проведении экспериментов по определению удельной эрозии электродов при газовом дуговом разряде вакуумный насос отсекали. Экспериментальная камера постоянно заполнялась газом до давления чуть выше атмосферного через игольчатый натекатель из нержавеющей стали. Газ постоянно обновлялся с расходом $0.1 \mathrm{l} / \mathrm{min}$. Применяемые газы имели следующие характеристики: азот по ГОСТ 9293-74, содержание азота не менее $99.99 \%$, содержание кислорода не более $0.001 \%$ объемной доли; аргон по ГОСТ 10157-79, первый сорт, содержание аргона не менее 99.987\%, содержание кислорода не более $0.002 \%$ объемной доли; аргон высокой чистоты по ТУ 2114-005-0024760-99, содержание аргона не менее $99.998 \%$, содержание кислорода не более $0.0002 \%$ объемной доли.

Электрическая дуга питалась от кабельного генератора. Длительность прямоугольного импульса питания дуги составляла $1.2 \mu \mathrm{s}$. Во избежание „завала“ фронта импульса питания дугового разряда электрические коаксиальные вводы экспериментальной камеры были согласованы с волновым сопротивлением генератора $\rho=75 \Omega$. Контрольными исследованиями была определена полоса пропускания электрических вводов вакуумной камеры, и система регистрации позволяла надежно наблюдать перепады напряжения фронтом длительностью $0.9 \mathrm{~ns}$. Индуктивность разрядной камеры оставляла $10 \mathrm{nH}$ и практически определялась индуктивностью проволочных электродов. Дуговой разряд зажигался острийным поджиговым электродом (диаметр острия меньше $5 \mu \mathrm{m}$ ), расположенным на расстоянии от 10 до $50 \mu \mathrm{m}$ от вершины катода, и к острию было приложено импульсное положительное напряжение амплитудой $20 \mathrm{kV}$ и длительностью $20 \mathrm{~ns}$. Ток поджигающего импульса был ограничен до 2 А с помощью резистора $R$, подключенного в цепь поджигающего импульса. Ток дугового разряда составлял 10 А и измерялся с помощью калиброванных резистивных шунтов. Величина и длительность импульса тока дугового разряда были известны для каждого импульса из осциллограмм, полученных осциллографами с полосой пропускания $10 \mathrm{GHz}$. Влияние поджигающего импульса тока на общую удельную эрозию незначительно, так как ток поджига в 5 раз меньше тока дуги и длительность тока поджига в 60 раз меньше времени горения дуги.

В процессе горения дуги за электродами велось визуальное наблюдение с помощью оптического микроскопа. Фотографированием вершины катода в оптическом микроскопе до и после серии импульсов горения дугового разряда определялось укорочение проволочного катода и оценивалась потеря его массы. Поверхности электродов и частицы были изучены растровыми электронными микроскопами (РЭМ) JSM-T220 и LEO 982. Просвечивающий электронный микроскоп (ПЭМ) JEM-2100 применялся для анализа наноразмерных частиц.

\section{2. Экспериментальные результаты и их обсуждение}

После экспериментов на поверхности анодов и поджигающих электродов не наблюдались следы существования анодных пятен и не были обнаружены капли катодного материала из-за переноса материала с катода на анод или на поджигающий электрод. Аноды и поджигающие электроды не вносили вклад в катодную эрозию. Особо надо отметить, что удельная эрозия катода в чистых вакуумных условиях в вакуумной дуге в наших экспериментальных условиях для вольфрамового катода составила $(2-4) \cdot 10^{-4} \mathrm{~g} / \mathrm{C}$. При увеличении давления аргона высокой чистоты от $10^{-6}$ до $10^{5} \mathrm{~Pa} \mathrm{в} \mathrm{слаботочной}$ дуге не происходит изменения скорости эрозии по сравнению с удельной эрозией в вакуумном дуговом разряде при чистых вакуумных условиях. Во время горения дугового разряда в атмосфере аргона технической чистоты скорость эрозии уменьшилась до 10\% по сравнению со скоростью эрозии при вакуумном дуговом разряде. Это уменьшение величины удельной эрозии может быть вызвано только образованием пленок загрязнений на поверхности катодов при введении в экспериментальную камеру газа с более высоким содержанием кислорода. 


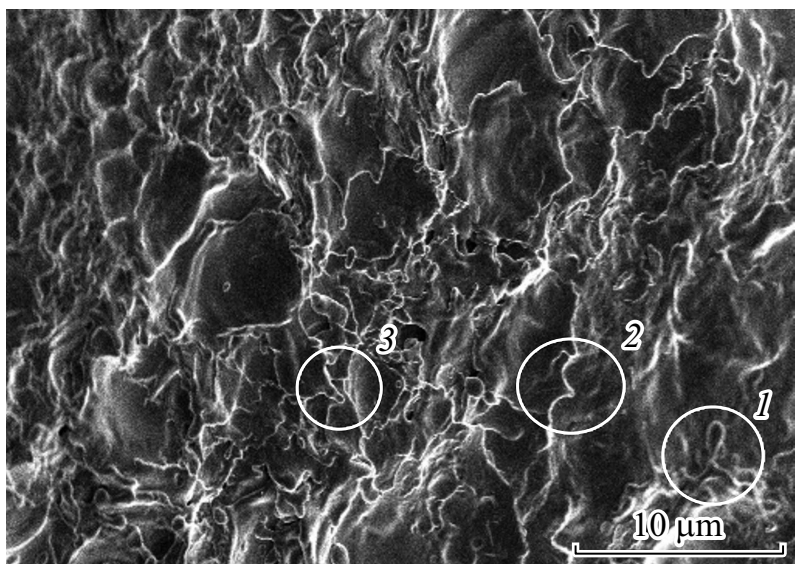

Рис. 2. Поверхность катода с застывшими кратерами и струями жидкого металла.

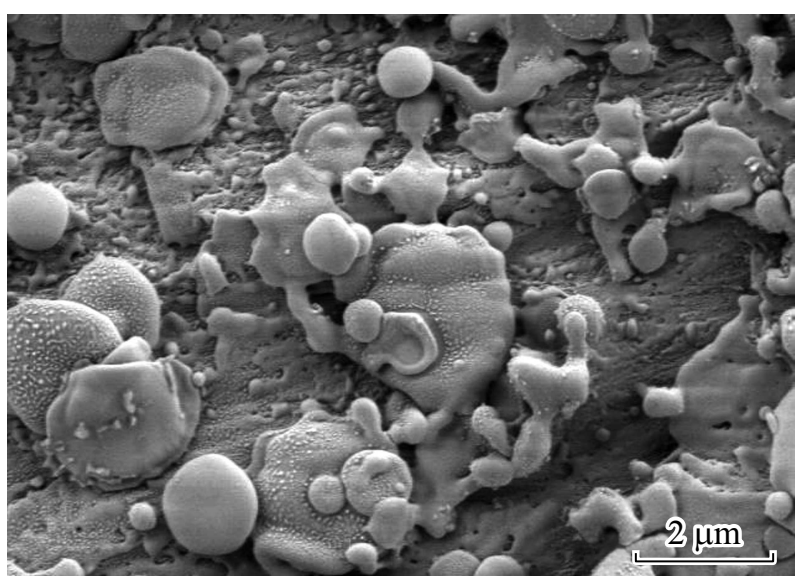

Рис. 3. РЭМ картина частиц после вакуумного дугового разряда.

Удельная эрозия во время дугового разряда в атмосфере азота уменьшилась от 15 до $35 \%$ по сравнению с удельной эрозией при вакуумном дуговом разряде. Содержание кислорода в азоте меньше по сравнению с аргоном технической чистоты. Поэтому такое уменьшение величины удельной эрозии может быть вызвано не только влиянием кислорода, но и образованием „загрязнений“ на поверхности катодов при введении в экспериментальную камеру азота.

Эти результаты дают веские основания для предположения, что поверхностные загрязнения играют важную роль в создании условий, ответственных за уменьшение тока, переносимого КП, и уменьшения скорости эрозии. Можно предположить, что отдельное КП, действующее при данном уровне тока в газе высокой чистоты имеет множество таких же основных характеристик, как отдельное КП, действующее при таком уровне тока в вакууме.

В процессе определения удельной эрозии изучалась и капельная составляющая эрозии. Капли образуются из-за разбрызгивания жидкого металла с поверхности катода из-за реактивного давления плазмы КП. Часть этого жидкого металла остается на поверхности катода в виде застывших струй, которые видны на рис. 2 (отмечены кругами). Практически все капли полетели на боковую поверхность. В вакууме капли отражаются от стенок экспериментальной камеры несколько раз, прежде чем остановиться на поверхности экспериментальной камеры или на специально установленном экране. Крупные капли в процессе удара распадались на более мелкие. Часть крупных капель, которые прилипли к поверхности экрана, деформированы при ударе и имеют плоскую форму, как видно на рис. 3. Это свидетельствует о том, что эти капли все еще находились в жидкой фазе при ударе о поверхность экрана и только после этого они затвердели. Однако не все капли деформированы. Частицы размером менее $0.5 \mu \mathrm{m}$ - сферические, что указывает на то, что они либо еще в полете остыли и затвердели до удара, либо после удара и прилипания еще жидких капель силы поверхностного натяжения вернули их в исходную сферическую форму и только после этого капли затвердели. До этого во многих исследованиях сообщалось, что нижний предел размера капель составлял около $0.1 \mu \mathrm{m}$. Этот нижний предел размера капель, видимо, связан с пространственным разрешением прибора формирования изображения (растрового электронного микроскопа или сканирующего туннельного микроскопа), а не с физически значимым пределом, и априори не было ясно, существует ли нижний предел размера частиц-капель. На самом же деле на рис. 3 видно присутствие частиц на поверхности коллектора и на поверхности крупных частиц размером менее $10 \mathrm{~nm}$.

В газовых дугах частицы из-за торможения в газе и уменьшения их скорости полета отражаются значительно меньше от стенок экспериментальной камеры по сравнению с вакуумным дуговым разрядом. Почти все частицы - сферические, и это указывает на то, что они были жидкими и остыли, сохранив свою форму. Характерная картина частиц после дугового разряда в аргоне представлена на рис. 4. Наиболее крупные капли имели размер меньше $3 \mu \mathrm{m}$. Характерная картина

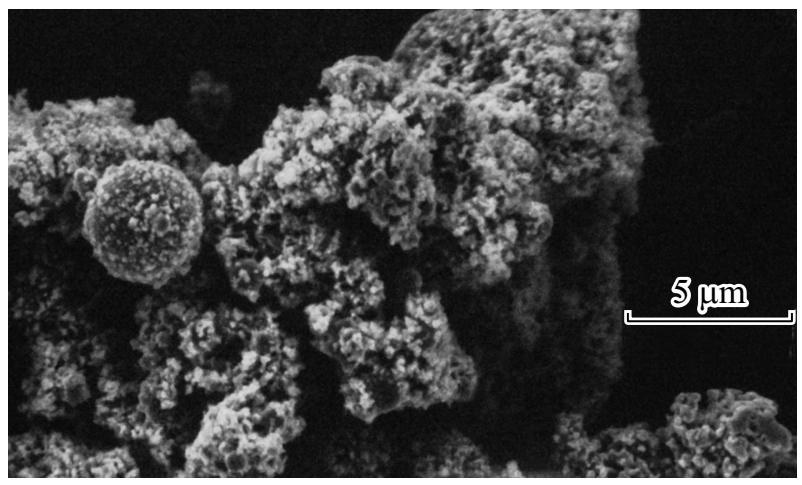

Рис. 4. РЭМ картина частиц после дугового разряда в аргоне. 


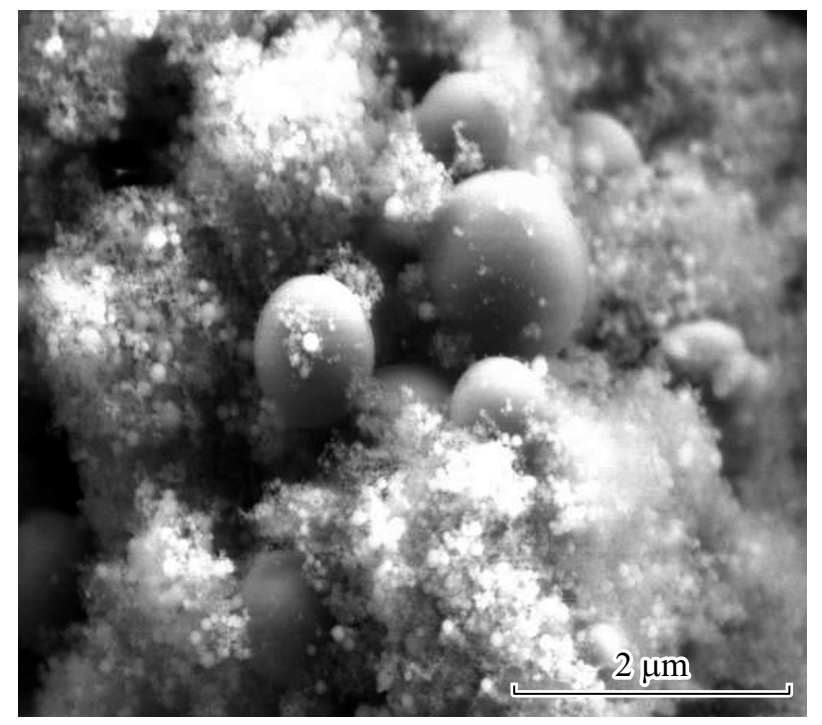

Рис. 5. РЭМ картина частиц после дугового разряда в азоте.

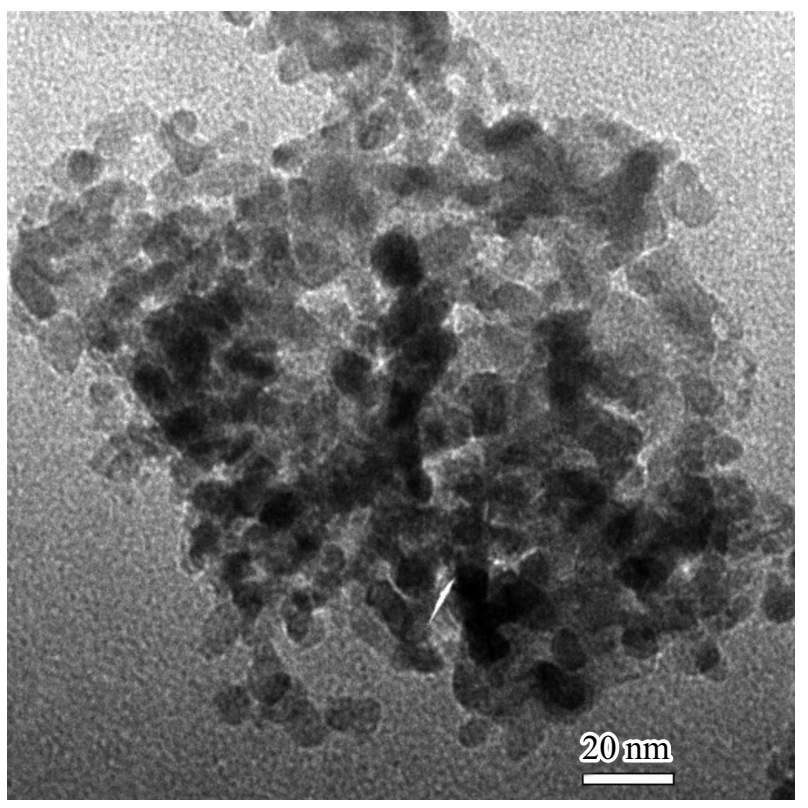

Рис. 6. ПЭМ картина наночастиц после газового дугового разряда.

частиц после дугового разряда в азоте представлена на рис. 5. Для анализа более мелкие частицы собирались на углеродной пленке, помещенной на медную сетку для просвечивающего электронного микроскопа. Несмотря на то что крупные капли рвали и пробивали эту углеродную пленку, удалось собрать для анализа необходимый материал. На рис. 6 представлена типичная фотография наночастиц. Средний размер частиц составляет порядка $60 \mathrm{~nm}$ и видны частицы размером 6-7 nm. Как правило, форма частицы близка к сферической. Исследование гранулометрического состава показало, что наночастицы имеют логнормальное распределение, средний геомет- рический размер частиц составлял $d_{g}=57 \mathrm{~nm}$. ПЭМ картина высокого разрешения наночастиц вольфрама показана на рис. 7,a. После обработки картины получение быстрого фурье-преобразования, наложения круговой маски на фурье-преобразование и инверсии получаем картину наночастицы с оксидной оболочкой (рис. 7, b).

Главной отличительной особенностью газовой дуги в отличие от вакуумной является образование большего количества частиц в нанометровом диапазоне. Этот результат можно объяснить так. Вблизи КП пар начинает конденсироваться с образованием наночастиц, дальше большая часть пара, расширяясь в вакууме, летит свободно, оседает на стенки экспериментальной камеры или на специально установленный экран и образует пленку. При горении дугового разряда в газе пар из материала катода тормозится окружающим газом. В инертном газе большая часть паров металла при остывании конденсируется и образует наночастицы. В газе, содержащем кислород, кроме процессов конденсации происходит и окисление (горение), а в азоте возможно образование нитридов. Поэтому при функционировании дугового разряда в газе количество частиц в нанометровом диапазоне больше.

Концепция подобия механизмов КП вакуумных и газовых дуг вполне вероятна. Величина удельной эрозии катодов дугового разряда в безмасляном вакууме и дугового разряда в аргоне высокой чистоты не отличаются. Значительные отличия результатов ранее сделанных экспериментов в скоростях эрозии дуг в вакууме и газовых дуг можно объяснить влиянием „активных“ поверхностных загрязнений. Есть вопросы, требующие понимания роли загрязняющей пленки. Пленки могут иметь толщину всего в несколько десятых нанометра, и они быстро разрушаются при высоких температурах КП. Но, несмотря на это, они играют важную роль в уменьшении среднего тока на пятно при высоких давлениях с соответствующим уменьшением удельной эрозии. Одним из возможных влияний поверхностных загрязнений является то, что они изменяют поверхностную работу выхода и что работа выхода может быть одним из факторов, влияющих на средний ток КП. Это подтверждается тем, что адсорбированный газ меняет работу выхода в автоэмиссионных наблюдениях.

В связи с развиваемой эктонной концепцией дуги [20] роль капель и струй жидкого металла в механизме функционирования КП существенно меняется. В работе [21] были исследованы эрозионные структуры на поверхности вольфрамового катода, сформированные при однократном горении вакуумной дуги током от 4 до $20 \mathrm{~A}$ и длительностью до $700 \mathrm{~ns}$. Было установлено, что средняя масса застывших выступов микронных размеров на поверхности катода равна массе ионов, удаленных с катода в течение горения ячейки КП. Время формирования новой жидкометаллической струи под действием реактивной силы плазмы КП составляет около $10 \mathrm{~ns}$, что 

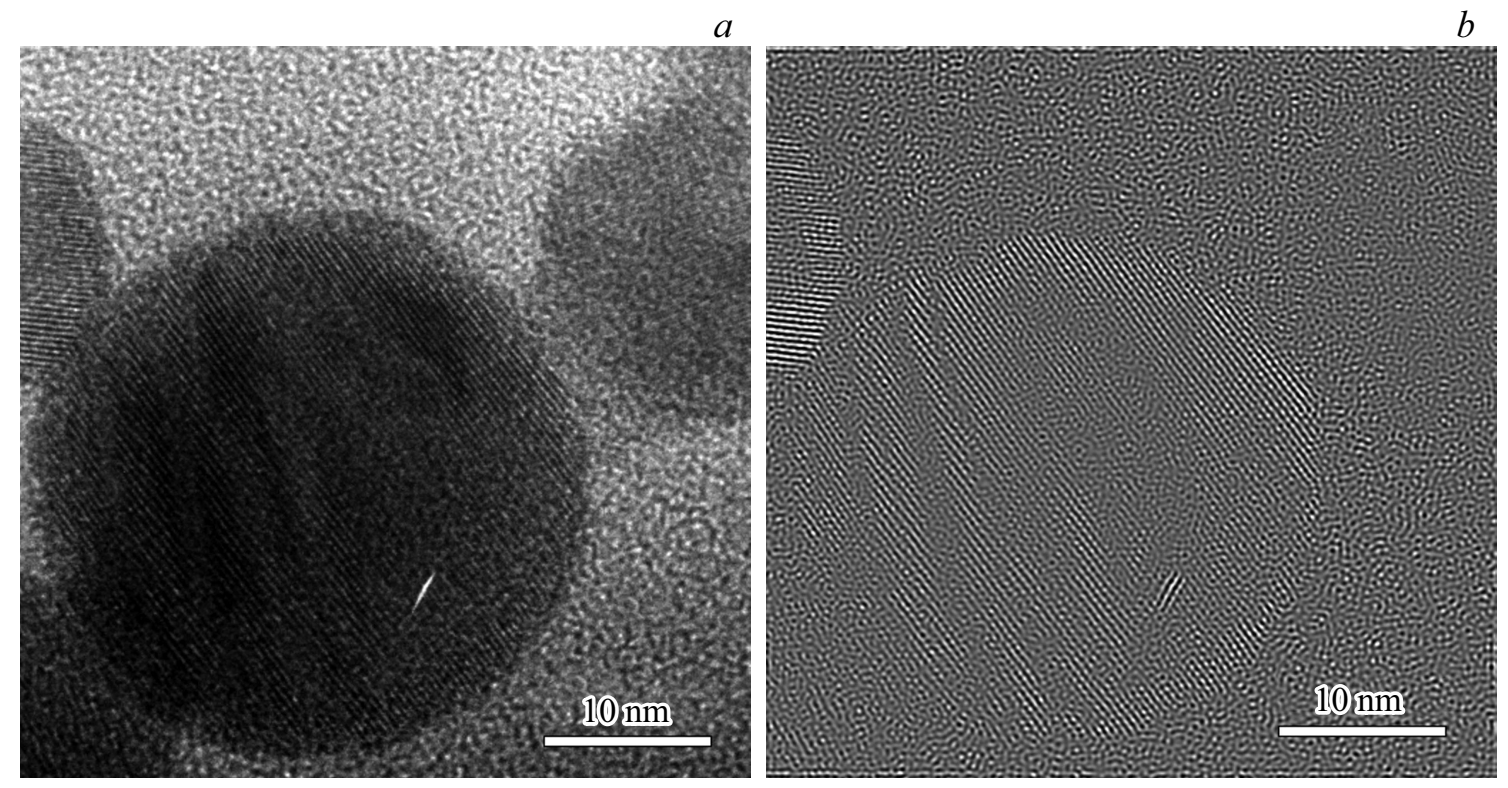

Рис. 7. ПЭМ картина высокого разрешения наночастиц вольфрама $(a)$ и картина наночастицы с оксидной оболочкой, полученная после обработки $(b)$.

сравнимо с временем жизни КП. Скорость роста жидкометаллической струи порядка $10^{2} \mathrm{~m} / \mathrm{s}$. Геометрическая форма и размер затвердевшей струи таковы, что новый взрывоэмиссионный центр может образоваться в течение нескольких наносекунд при взаимодействии струи с плотной катодной плазмой. Это является основным механизмом самоподдерживания вакуумной дуги.

В связи с этим были тщательно рассмотрены эрозионные структуры на поверхности катода, образованные в результате воздействия КП дуги в чистом аргоне (рис. 2). Несмотря на многократные дуговые разряды и наложения следов эрозии друг на друга, эрозионные следы КП содержат большое количество застывших выступов. Они не отличаются от эрозионных следов вакуумной дуги. На рис. 2 (в кружках 1-3) можно увидеть застывшие струи и неотделенные капли. Это позволяет предположить, что струи микронного размера на заключительном этапе их развития представляли собой жидкометаллические выступы. Оцененная по методике, описанной в [20], средняя масса микровыступов (застывших струй) на поверхности катода по порядку величины равна массе ионов, удаленных с катода в течение одного цикла горения ячейки КП током в 10 А на одном месте.

В [22] гидродинамический анализ поведения „лужицы“ жидкого металла в области КП позволил оценить пороговые значения давления плазмы и протекающего через кратер электрического тока, при котором жидкий металл начинает выплескиваться в виде струй и капель. Было показано, что кратер может быть сформирован выдавливанием жидкого металла плазмой за $30 \mathrm{~ns}$, если плотность теплового потока выше $10^{12} \mathrm{~W} / \mathrm{m}^{2}$ и давление выше $10^{8} \mathrm{~Pa}$. Такая величина давления сравнима с давлением на дне Марианской впадины. А посему внешнее давление газа в экспериментальной установке должно оказывать слабое (незначительное) влияние на физические процессы в КП.

\section{Заключение}

Результаты исследований показали, что величина удельной эрозии вольфрамовых катодов в дуговом разряде в атмосфере аргона высокой чистоты не меняется по сравнению с величиной удельной эрозии в дуговом разряде в безмасляном вакууме. Увеличение содержания кислорода даже на одну тысячную долю процента в аргоне способствует уменьшению удельной эрозии до $10 \%$. Удельная эрозия катода в дугах азота меньше удельной эрозии в вакуумных дугах. Полагаем, что поверхностные загрязнения, привнесенные газом, играют важную роль в создании условий, ответственных за уменьшение тока, переносимого одним КП, и это приводит к уменьшению удельной эрозии. Размер частиц после газовых дуг меньше размера частиц после вакуумных дуг. Размер наночастиц в дугах азота меньше, чем размер наночастиц в дугах аргона. Образование наночастиц в газовой дуге больше, чем в вакуумной дуге.

Эрозионные структуры на поверхности катода (кратеры, застывшие струи и неотделенные капли), образованные в результате воздействия КП дуги в чистом аргоне, не отличаются от эрозионных структур вакуумной дуги. Можно констатировать, что взаимодействие КП с жидкими металлическими выступами на поверхности катода неизбежно приводит к взрывной эмиссии электронов. По-видимому, капли, струи и плазма тоже обеспечивают процесс самоподдержания газовой дуги. 
Мы предполагаем, что отдельное КП, действующее при данном уровне тока в аргоне высокой чистоты, имеет множество таких же основных характеристик, как отдельное КП, действующее при таком уровне тока в чистых вакуумных условиях. Концепция подобия механизмов функционирования КП как вакуумных дуг, так и дуг высокого давления представляется вполне правдоподобной.

\section{Благодарности}

Работа выполнена с использованием оборудования ЦКП ИЭФ УрО РАН.

\section{Финансирование работы}

Настоящая работа выполнена в рамках темы государственного задания № АААА-А18-118030290007-5 и № AAAA-A18-118030290006-8.

\section{Конфликт интересов}

Автор заявляет, что у него нет конфликта интересов.

\section{Список литературы}

[1] Ю.П. Райзер. Физика газового разряда (Наука, М., 1987)

[2] R.N. Szente, R.J. Munz, M.G. Drouet. Plasma Chem. Plasma Proces., 12 (3), 327 (1992). DOI: 10.1007/bf01447029

[3] J.L. Meunier, M.G. Drouet. IEEE Trans. Plasma Sci., 15 (5), 515 (1987). DOI: 10.1109/tps.1987.4316746

[4] C.W. Kimblin. J. Appl. Phys., 44, 3074 (1973). DOI: $10.1063 / 1.1662710$

[5] C.W. Kimblin. J. Appl. Phys. 45, 5235 (1974). DOI: $10.1063 / 1.16632222$

[6] J.E. Daalder. J. Phys. D: Appl. Phys., 8, 1647 (1975). DOI: $10.1088 / 0022-3727 / 8 / 14 / 009$

[7] J.E. Daalder. J. Phys. D: Appl. Phys., 9, 2379 (1976). DOI: 10.1088/0022-3727/9/16/009

[8] A. Anders, E.M. Oks, G.Y. Yushkov, K.P. Savkin, I.G. Brown, A.G. Nikolaev. IEEE Transactions on Plasma Sci., 33 (5), 1532 (2005). DOI: 10.1109/tps.2005.856502

[9] S. Anders, A. Anders, R.M. Yu, X.Y. Yao, I.G. Brown. IEEE Trans. Plasma Sci., 21 (5), 440 (1993). DOI: $10.1109 / 27.249623$

[10] W.D. Davis, H.C. Miller. J. Appl. Phys., 40 (5), 2212 (1969).

[11] M.G. Drouet, J.L. Meunier. IEEE Trans. Plasma Sci., 13, 285 (1985). DOI: 10.1109/TPS.1985.4316421

[12] J.L. Meunier, M.G. Drouet. IEEE Trans. Plasma Sci., 15 (5), 515 (1987). DOI: $10.1109 /$ tps.1987.4316746

[13] J.L. Meunier. IEEE Trans. Plasma Sci., 18 (6), 904 (1990). DOI: $10.1109 / 27.61501$

[14] R.L. Boxman, S. Goldsmith. IEEE Trans. Plasma Sci., 18 (2), 231 (1990). DOI: 10.1109/27.131026

[15] D.R. Porto, C.W. Kimblin, D.T. Tuma. Appl. Phys., 53 (7), 4740 (1982). DOI.org/10.1063/1.331302

[16] S. Anders, B. Juttner. IEEE Trans. Plasma Sci., 19 (5), 705 (1991). DOI: $10.1109 / 27.108402$

[17] B. Juttner. J. Phys., IV, 07 (C4), C4-31 (1997). DOI: $10.1051 / j p 4: 1997404$
[18] B. Juttner. J. Phys. D: Appl. Phys., 34, 103 (2001).

[19] Ф. Розбери. Справочник по вакуумной технике и технологии (Энергия, М., 1972) [F. Rosebury. Handbook of Electron Tube and Vacuum Techniques (Massachusetts, 1964)]

[20] Г.А. Месяц. Эктоны в вакуумном разряде: пробой искра, дуга (Наука, М., 2000)

[21] G.A. Mesyats, M.B. Bochkarev, A.A. Petrov, S.A. Barengolts. Appl. Phys. Lett., 104, 184101 (2014). DOI: $10.1063 / 1.4874628$

[22] G.A. Mesyats, I.V. Uimanov. IEEE Trans. Plasma Sci., 43 (8), 2241 (2015). DOI: 10.1109/TPS.2015.2431317 